\title{
Exfoliation of Sheet Silicates by Nitroxide Mediated Polymerization
}

\author{
Andreas Mühlebach*, Peter Nesvadba*, François Rime, and Lucienne Bugnon
}

\begin{abstract}
A new cationic alkoxyamine initiator/regulator for the nitroxide-mediated polymerization of acrylates was prepared and intercalated by cation exchange into a montmorillonite-type natural and a synthetic layered silicate. Thermal activation of this alkoxyamine in the presence of $n$-butyl acrylate as monomer initiated its controlled radical polymerization, leading to an almost complete exfoliation of the silicate layers. The poly(n-butyl-acrylate) chains attached to the individual sheet silicate layers showed adjustable number average molecular weights $\left(M_{n}\right)$ values between 1000 and $14000 \mathrm{~g} / \mathrm{mol}$ and polydispersities PD $\left(=M_{w} / M_{n} ; M_{w}=\right.$ weight average molecular weight $)$ as low as 1.5. The poly(n-butyl acrylate) modified silicate nanoparticles obtained by this process have a polymer content between 41 and $89 \mathrm{wt}$ \%, are non-agglomerated and stable in dispersion for $>1$ year without any sedimentation. They are easily re-dispersible in apolar solvents, in monomers and macromonomers which are used e.g. in coating formulations and in polymer solutions/melts, forming nanocomposites with novel properties. For example, a $20 \%$ reduction of the $\mathrm{O}_{2}$ permeability of polyethylene films was observed at $5 \mathrm{wt} \%$ loading with the exfoliated sheet silicate.
\end{abstract}

Keywords: Alkoxyamines · Controlled/living radical polymerization · Exfoliation · Layered silicates ·

Nanocomposites

\section{Introduction}

Polymer/layered silicates (clay) nanocomposites, combining the characteristics of both materials at the nanoscale level, have recently found considerable industrial and academic interest for improvement of diverse properties of a variety of polymers or coatings. For example, polymer/layered silicates nanocomposites were shown to possess enhanced mechanical strength, higher barriers to gas permeation, better electrical insulation or lower flammability.[1-7] The property enhancements are attributed to the large interface areas between the silicate platelets and the host polymer matrix. The special interest in layered (sheet) silicates arises from their low price and good

${ }^{\star}$ Correspondence: Dr. A. Mühlebach; Dr. P. Nesvadba Tel.: +4161636 2427; +41616362412

E-mail: andreas.muehlebach@cibasc.com; peter.nesvadba@cibasc.com

Ciba, R\&D Coating Effects and Group Research

Klybeckstrasse 141

$\mathrm{CH}-4002$ Basel availability, the anisometric particle shape with a high aspect ratio (typically $>200$ ), the unique layered crystal structure and the fact that the thickness of the individual layers is in the nanometer range (ca. $1 \mathrm{~nm})$. However, a prerequisite for optimal properties of the nanocomposite is good dispersion and excellent spatial distribution of the silicate nanofiller in the polymeric matrix material. This approach requires deagglomeration and delamination (or exfoliation) of the individual silicate layers which are held together by electrostatic forces into stacked agglomerates in the original clay. Moreover, a suitable functionalization of the delaminated hydrophilic clay layers is needed to increase the compatibility (wetting) between the hydrophilic silicate layers and the - in general - hydrophobic polymer matrix. To this purpose, various pretreatments of the clay silicates, such as for example treatment of the clay with silane coupling agents ${ }^{[8]}$ or replacement of the clay interlayer metal cations with hydrophobic organic cations ${ }^{[9]}$ were developed. Yet another possibility consists of growing the polymeric chain from the surface of the layered silicate. To do this, the clay is intercalated by suitable organic cations, carrying a reactive group (initiator, monomer) that can participate in the polymerization and promote thus exfoliation and separation of the clay layers. ${ }^{[10-12]}$ Hence, the interac- tions between the silicate layers are minimized and no periodic stacking is observed. Additionally, an appropriate choice of the polymer provides a methodology to tailor the compatibility of the layered silicate with the matrix.

In this work we used the semi-commercial montmorillonite-type layered silicate Nanofil EXM 588 and the commercial synthetic sheet silicate Optigel SH. Both materials consist of negatively charged $\mathrm{Si}$ / Al-oxide layers and single charged $\mathrm{Na}^{+}$and $\mathrm{K}^{+}$cations which are located in the galleries between these layers ${ }^{[13,14]}$ and are characterized by a relatively high ion exchange capacity and a large specific surface area. The $\mathrm{Na}^{+}$and $\mathrm{K}^{+}$ions between the silicate layers are prone to exchange with other cations in an equilibrium reaction. The driving force of this reaction is the gain of solvation enthalpy of the liberated cations relative to the intercalated ones and therefore the cation exchange is best performed in water with amphiphilic organic cations. ${ }^{[15]}$ Thus, modified montmorillonite-type sheet silicates with interlayer distance of $c a$. $1.5-2.5 \mathrm{~nm}$ are readily accessible by intercalation with organic cations (onium ions).

Some time ago we synthesized and intercalated symmetric dicationic peroxide initiators into layered silicates and studied their potential to induce silicate exfoliation by uncontrolled radical polymerization. ${ }^{[16]}$ 
However, initiator efficiency was very low. In fact, we estimated that only one out of 500 initiator molecules is active in polymerization and GPC analysis of the polymer showed a high molecular weight $\left(M_{n}>10^{5}\right.$ $\mathrm{g} / \mathrm{mol}$ ) combined with very high polydispersity (PD $>5$ ). Therefore, not surprisingly, the exfoliation was incomplete.

On the other hand, the controlled/living radical polymerization (CRP) is an excellent method to control the polymer molecular weight and architecture ${ }^{[17]}$ and is - in contrast to other living polymerization methods - tolerant to impurities and moisture which are present in the naturally occurring sheet silicates. The most versatile CRP methods are atom-transfer radical polymerization (ATRP), reversible radical additionfragmentation chain transfer (RAFT) and nitroxide-mediated radical polymerization (NMP). The underlying principle of these CRP techniques is the reversible activation/ deactivation of the propagating radicals. In the case of NMP it is the reversible combination of propagating radicals with nitroxide radicals ${ }^{[18,19]}$ (Scheme 1).

A great number of publications report the use of all three CRP techniques to grow polymer brushes from planar substrates or nanoparticles including silica, aluminium or iron oxides, quantum dots or gold colloids but only a few works exist on clay minerals.[20,21] Sogah and coworkers showed in a preliminary communication ${ }^{[22]}$ that polystyrene chains could be grown from the surface of montmorillonite via NMP, using an intercalated cationic tetramethyl-piperidine derived alkoxyamine NMP initiator. In a more recent paper[23] they described the grafting of poly(styrene$\varepsilon$-caprolactone) diblock copolymers from the clay layers using an initiator anchored on the clay layers and capable of initiating simultaneously the ring-opening polymerization of $\varepsilon$-caprolactone and NMP of styrene. Very recently, Bourgeat-Lami and coworkers applied NMP using a quaternary ammonium alkoxyamine initiator prepared from N-tert-butyl-N-[1-diethylphosphono(2,2-dimethylpropyl)-nitroxide (2, Fig. 1) to grow polystyrene chains with controlled molecular weight and relatively low polydispersities (PD >1.5) from the surface of Laponite clay. [20]

In this article, we report the, to the best of our knowledge, first montmorillonite exfoliation via NMP of n-butylacrylate using novel cationic alkoxyamine intercalated into montmorillonite by cation exchange. At the beginning of CRP only styrene monomers could be polymerized in a controlled way by NMP. In the past few years, several new nitroxides, allowing the controlled polymerization of other monomers, most importantly of acrylates, acrylonitrile or acrylamides, were introduced. Amongst the most significant (Fig. 1) are open chain

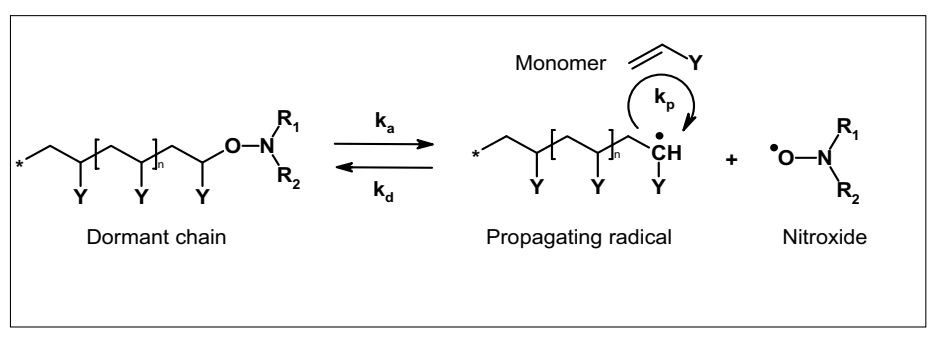

Scheme 1. Nitroxide-mediated polymerization (NMP)

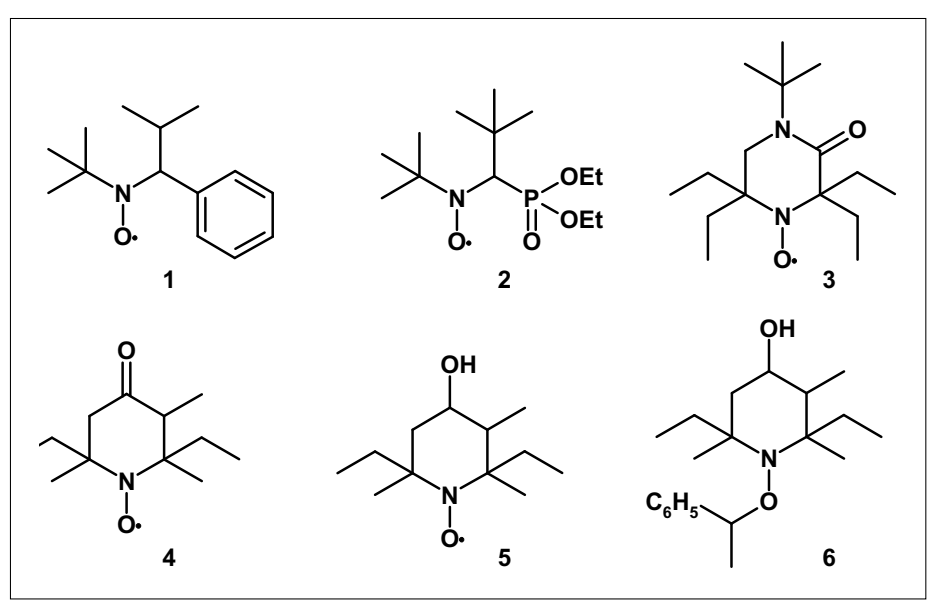

Fig. 1. Nitroxides and alkoxyamines for NMP of acrylates nitroxides, 1,1-dimethylethyl 2-methyl-1phenylpropyl nitroxide (1, TIPNO) ${ }^{[24]}$ or the above-mentioned N-tert-butyl-N-[1-diethylphosphono-(2,2-dimethylpropyl)-nitroxide (2, DEPN, SG-1).[25] In our laboratories were developed sterically highly hindered

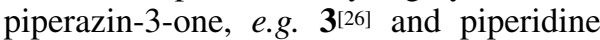
nitroxides and the related alkoxyamines, e.g. compounds 4-6. ${ }^{[27,28]}$ The latter are now used in the industrially applied NMP process $^{[29-31]}$ to produce acrylate block-copolymers with controlled molecular weight, block composition and low polydispersity. Building on these developments, we used the nitroxide $\mathbf{5}$ and transformed it into the alkoxyamine 8 via $\mathrm{Cu}(\mathrm{I})$-promoted coupling with the readily available (see Experimental Section) bromoamide 7. Quaternization of $\mathbf{8}$ with benzylchloride afforded the desired cationic alkoxyamine NMP-initiator 9 (Scheme 2). In this article we present detailed results of the exfoliation of a natural (montmorillonite-type) and a synthetic sheet silicate with the alkoxyamine $\mathbf{9}$ and n-butyl acrylate as monomer. The synthesis of additional cationic alkoxyamines derived from $3, \mathbf{4}$ or $\mathbf{5}$ and the corresponding exfoliation experiments have been published in our recent patent application. ${ }^{[32]}$

\section{Experimental}

\subsection{Materials and Instruments}

Solvents, reagents and monomers are all commercially available and were used as received. $\mathrm{Na}^{+}$-montmorillonite (Nanofil EXM 588), a natural sheet silicate, was obtained from Süd-Chemie AG, Germany, as a greyish powder. The cation exchange capacity was specified to be $0.61 \mathrm{mmol} / \mathrm{g}$ and the interlayer distance is $0.98 \mathrm{~nm}$. Op-

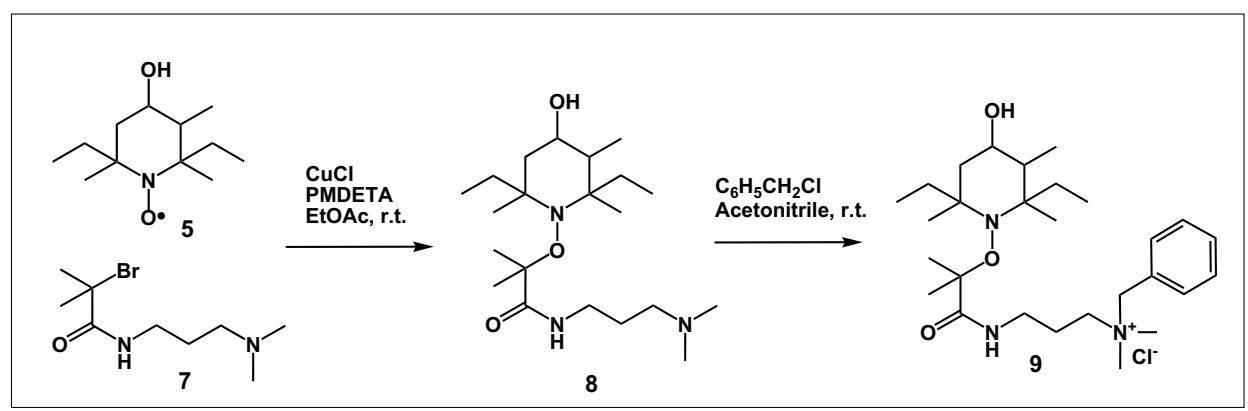

Scheme 2. Synthesis of the cationic alkoxyamine 9 
tigel $\mathrm{SH}$, a synthetic sheet silicate with a cation exchange capacity of $0.78 \mathrm{mmol} / \mathrm{g}$, was also obtained from Süd-Chemie as a white powder. Centrifugation was done in 100-180 ml glass vessels in an IEC Centra GP8 centrifuge at approx. $2000 \mathrm{rpm}$ (corresponding to $c a .850 \mathrm{~g}$ ). ${ }^{1} \mathrm{H}$ - and ${ }^{13} \mathrm{C}$ NMR spectra were measured on a Bruker Avance 300 NMR spectrometer and referenced to $\mathrm{SiMe}_{4}$ ( $\delta$ in ppm, $J$ in $\mathrm{Hz}$ ). IR spectra were taken on Nicolet Magna-IR 750 spectrometer in $\mathrm{KBr}$ pill, MS spectra on Finnigan SSQ 710 apparatus. Molecular weights $\left(M_{n}, M_{w}\right)$ and polydispersity $\left(\mathrm{PD}=\mathrm{M}_{\mathrm{w}} / \mathrm{M}_{\mathrm{n}}\right)$ were measured by GPC in THF on a PL Gel (Polymer Laboratories) guard and $2 \times 5 \mu \mathrm{m}$ mixed bed $\mathrm{C}$ columns $\left(40{ }^{\circ} \mathrm{C}\right)$ with a Waters $600 \mathrm{E}$ pump and controller and a Waters 410 RI detector. The values are relative to monodisperse PS standards. Thermogravimetric analyses (TGA) were performed under air on a Mettler Toledo TC15 TA instrument and controller with a heating rate of $10{ }^{\circ} \mathrm{C} /$ min. Elemental analyses were obtained from the Ciba Service Center Elemental Analysis. Residual solvent molecules were identified by ${ }^{1} \mathrm{H}-\mathrm{NMR}$. Powder $\mathrm{X}$-ray measurements were performed on a Siemens D500 diffractometer with monochromatic $\mathrm{Cu}-K_{\alpha}$ radiation $(\lambda=$ $1.5418 \AA$ ) at a scanning rate of $0.3^{\circ} \% \mathrm{~min}$. Oxygen permeability measurements were done on sheet silicate loaded polyethylene (PE) films at the Frauenhofer Institute for Chemical Engineering and Packaging (D-85354 Freising) according to DIN 53 380 (T3). The PE pellets (Lupolen 2420 from BASF) were extruded with 3-5\% exfoliated sheet silicates at $180{ }^{\circ} \mathrm{C}$ and the melt blown at $200{ }^{\circ} \mathrm{C}$ to an approx. $30 \mu \mathrm{m}$ thick film. The oxygen diffusing through this film was measured with a chemical sensor.

\subsection{2-Bromo-N- (3-dimethylaminopropyl)-2- methylpropionamide (7)}

2-Bromoisobutyryl bromide (23.0 g, 0.1 mol) was added dropwise over $50 \mathrm{~min}$ to a solution of 3-dimethylaminopropylamine $(25.2 \mathrm{ml}, 0.2 \mathrm{~mol})$ in THF $(50 \mathrm{ml})$, while keeping the temperature between $0-10{ }^{\circ} \mathrm{C}$. The mixture was stirred for another $3 \mathrm{~h}$ at room temperature and the THF was then evaporated in vacuo. Water $(20 \mathrm{ml})$ was added to the residue and the mixture was extracted with $t$-butyl-methyl ether $(2 \times 30$ $\mathrm{ml})$ and ethylacetate $(30 \mathrm{ml})$. The combined extracts were washed with saturated $\mathrm{NaCl}$ solution $(10 \mathrm{ml})$, dried over $\mathrm{MgSO}_{4}$ and evaporated to afford $24.1 \mathrm{~g}(96 \%)$ of the title compound as colorless oil.

${ }^{1} \mathrm{H}-\mathrm{NMR}\left(300 \mathrm{MHz}, \mathrm{CDCl}_{3}\right): 8.51$ (bs, $\mathrm{NH}), 3.39-3.34\left(\mathrm{~m}, \mathrm{CH}_{2}\right), 2.45(\mathrm{t}, J=6 \mathrm{~Hz}$, $\left.\mathrm{CH}_{2}\right), 2.25\left(\mathrm{~s}, 2 \times \mathrm{CH}_{3}\right), 1.94\left(\mathrm{~s}, 2 \times \mathrm{CH}_{3}\right)$, 1.72-1.64 (m, $\left.\mathrm{CH}_{2}\right)$.
2.3. 2-(2,6-Diethyl-4-hydroxy-2,3,6trimethyl-piperidine-1-yloxy)- $N$ (3-dimethylamino-propyl)-2-methylpropionamide (8)

To a solution of 2,6-diethyl-2,3,6trimethyl-piperidine-4-hydroxy-N-oxyl (5, $12.86 \mathrm{~g}, 60 \mathrm{mmol}$, prepared as described in ref. [28]) in EtOAc (50 ml) was added under argon $\mathrm{CuCl}(11.9 \mathrm{~g}, 120 \mathrm{mmol})$ and 2-bromo-N-(3-dimethylamino-propyl)-2methyl-propionamide $(7,16.5 \mathrm{~g}, 66 \mathrm{mmol})$. Then, N,N,N',N",N''-pentamethyl-diethylene-triamine (PMDTA) $(20.8 \mathrm{~g}, 120 \mathrm{mmol})$ was added dropwise within 55 min while keeping the temperature at $35-38{ }^{\circ} \mathrm{C}$. The mixture was then stirred $15 \mathrm{~h}$ at room temperature under argon. The green suspension was filtered and the filter cake was washed with $100 \mathrm{ml}$ ethyl acetate. The filtrate was washed successively with $3 \times 50 \mathrm{ml}$ water $50 \mathrm{ml}$ of a $1 \%$ aqueous EDTA-disodium salt solution, $50 \mathrm{ml}$ water, $50 \mathrm{ml}$ saturated $\mathrm{NaCl}$ solution, dried over $\mathrm{MgSO}_{4}$ and evaporated, finally at $0.01 \mathrm{mbar} / 50{ }^{\circ} \mathrm{C}$ to afford $23 \mathrm{~g}$ $(99.4 \%)$ of $\mathbf{8}$ as a slightly yellow thick oil.

${ }^{1} \mathrm{H}-\mathrm{NMR}\left(300 \mathrm{MHz}, \mathrm{CDCl}_{3}\right)$, mixture of diastereoisomers: 7.37-7.25 (bs, $\mathrm{NH}), 4.19-4.11(\mathrm{~m}, \mathrm{CH}(\mathrm{OH})), 3.60-3.10$ $\left(\mathrm{m}, \mathrm{CH}_{2}\right), 2.35-2.25\left(\mathrm{~m}, \mathrm{CH}_{2}\right), 2.23(\mathrm{~s}$, $\left.\mathrm{N}\left(\mathrm{CH}_{3}\right)_{2}\right), 2.10-0.79(\mathrm{~m}, 31 \mathrm{H})$.

Single spot on TLC (silica gel plate, EtOAc-MeOH 1:1, Rf=0.2).

\subsection{Benzyl-[3-[2-(2,6-diethyl-4- hydroxy-2,3,6-trimethylpiperidin-1- yloxy)-2-methylpropionyl-amino]- propyl]-dimethylammonium chloride (9)}

Benzylchloride $(0.87 \mathrm{~g}, 6.87 \mathrm{mmol})$ was added to a solution of $\mathbf{8}(2.2 \mathrm{~g}, 5.7 \mathrm{mmol})$ in acetonitrile $(3 \mathrm{ml})$. The mixture was stirred for $19 \mathrm{~h}$ at room temperature and then evaporated. The residue was treated with diethylether to remove the excess of benzylchloride, the solid was filtered off and dried to afford $2.9 \mathrm{~g}(99 \%)$ of the title compound as a colorless amorphous solid.

MS (Infusion-ESI) for the cation $\mathrm{C}_{28} \mathrm{H}_{50} \mathrm{~N}_{3} \mathrm{O}_{3}$ (476.73): found $\mathrm{M}^{+}=476.4$. ${ }^{1} \mathrm{H}-\mathrm{NMR}\left(300 \mathrm{MHz}, \mathrm{CDCl}_{3}\right)$, mixture of diastereoisomers: $7.70-7.55(\mathrm{~m}, 2 \mathrm{ArH})$, 7.50-7.30 (m, $3 \mathrm{ArH}), 7.05-6.85$ (bs, NH), 4.91 (bs, $\left.\mathrm{CH}_{2} \mathrm{Ph}\right), 4.30-4.10(\mathrm{~m}, \mathrm{CH}(\mathrm{OH})$, $3.70-3.50\left(\mathrm{~m}, \mathrm{CH}_{2}\right), 3.34\left(\mathrm{~s}, \mathrm{~N}^{+}\left(\mathrm{CH}_{3}\right)_{2}\right)$, $2.50-0.60(\mathrm{~m}, 33 \mathrm{H})$.

\subsection{Bulk Polymerization of n-Butylacrylate with the Alkoxyamines 8 and 9}

A $50 \mathrm{ml}$ three-necked round bottom flask with $\mathrm{N}_{2}$ in- and outlet, reflux condenser and magnetic stirring was charged with $10 \mathrm{~g}$ (78 mmol) n-butyl acrylate, $0.451 \mathrm{~g}$ (1.17 mmol, $1.5 \mathrm{~mol} \%)$ of the alkoxyamine 8 resp. $0.599 \mathrm{~g}(1.17 \mathrm{mmol}, 1.5 \mathrm{~mol} \%)$ of 9 and $2 \mathrm{~g}$ N,N-dimethyl-acetamide. The solution was deoxygenated by five evacuation/ nitrogen purging cycles and then heated with an oil bath under nitrogen to $140^{\circ} \mathrm{C}$ for $7 \mathrm{~h}$. The conversion was determined by ${ }^{1} \mathrm{H}-$ NMR (integration of residual monomer vs. polymer signals) and the molecular weight and polydispersity was measured by GPC.

8: Conversion $71 \%, \mathrm{M}_{\mathrm{n}}=6150$ (predicted $\left.M_{n}=6390\right), P D=1.21,9:$ Conversion $65 \%, M_{n}=6270\left(\right.$ predicted $\left.M_{n}=6010\right), P D$ $=1.34$.

\subsection{Intercalation of 9 into the Layered Silicate 'Nanofil EXM 588' (Montmorillonite-type) (Scheme 3)}

$60 \mathrm{~g}$ (116.9 mmol, 1.2 equiv. relative to the ion-exchange capacity of the sheet silicate) 9 was dissolved in a mixture of 850 $\mathrm{ml}$ distilled water and $150 \mathrm{ml} \mathrm{EtOH}$. 159.6 g Nanofil EXM 588 (containing 12.6 wt.\% water[33]) was dispersed in this solution and stirred for $24 \mathrm{~h}$ at room temperature. [34] The dispersion was centrifuged for $1 \mathrm{~h}$, the wet residue dispersed again in $500 \mathrm{ml}$ water/EtOH (85/15) and centrifuged. This procedure was repeated two more times, the last time with pure $\mathrm{EtOH}$. The product was dried in vacuo $\left(3 \mathrm{~d}, 50{ }^{\circ} \mathrm{C}, 0.01 \mathrm{mbar}\right)$. Yield: $184 \mathrm{~g}$ of a grey powder.

Weight loss determined by TGA (50$600{ }^{\circ} \mathrm{C}$ ): $27.1 \mathrm{wt} \%$, corresponding to 56.9 mmol 9 in $100 \mathrm{~g}$ intercalated sheet silicate. Powder X-ray analysis gave a main reflection peak at $2 \Theta=3.86^{\circ}$ (Fig. 2b), the original strong reflection peak at $2 \Theta=7.1^{\circ}$ (Fig. 2a) has disappeared.

\subsection{Intercalation of 9 into the Synthetic Layered Silicate 'Optigel SH'}

$60.25 \mathrm{~g}$ (117.4 mmol, 1.2 equiv. relative to the ion exchange capacity of the sheet silicate) 9 was dissolved in a mixture of 850 $\mathrm{ml}$ distilled water and $150 \mathrm{ml} \mathrm{EtOH.} 125.4$ g Optigel SH (containing 15 wt.\% water ${ }^{[35]}$ ) was dispersed in this solution and stirred for $24 \mathrm{~h}$ at r.t. The dispersion was filtered, washed with water and dried in vacuo $(3 \mathrm{~d}$, $\left.50{ }^{\circ} \mathrm{C}, 0.01 \mathrm{mbar}\right)$. Yield: $154.2 \mathrm{~g}$ of a white powder.

Weight loss determined by TGA $(50$ $600{ }^{\circ} \mathrm{C}$ ): $31.5 \mathrm{wt} \%$, corresponding to 66.1 mmol 9 in $100 \mathrm{~g}$ intercalated synthetic sheet silicate.

\subsection{Exfoliation of Natural Sheet Silicate Nanofil EXM 588 Containing the Intercalated Cationic Alkoxyamine 9 via NMP of n-Butyl Acrylate (Scheme 3) \\ In a typical example, $57.8 \mathrm{~g}$ Nanofil} EXM 588 intercalated with alkoxyamine 9 (32.9 mmol) was dispersed in a mixture of $308 \mathrm{~g}$ (2.4 mol) n-butyl acrylate and $924 \mathrm{~g}$ 2-methoxypropyl acetate and homogenized with an ultraturrax mixer and ultrasonic bath. The dispersion was transferred to a 


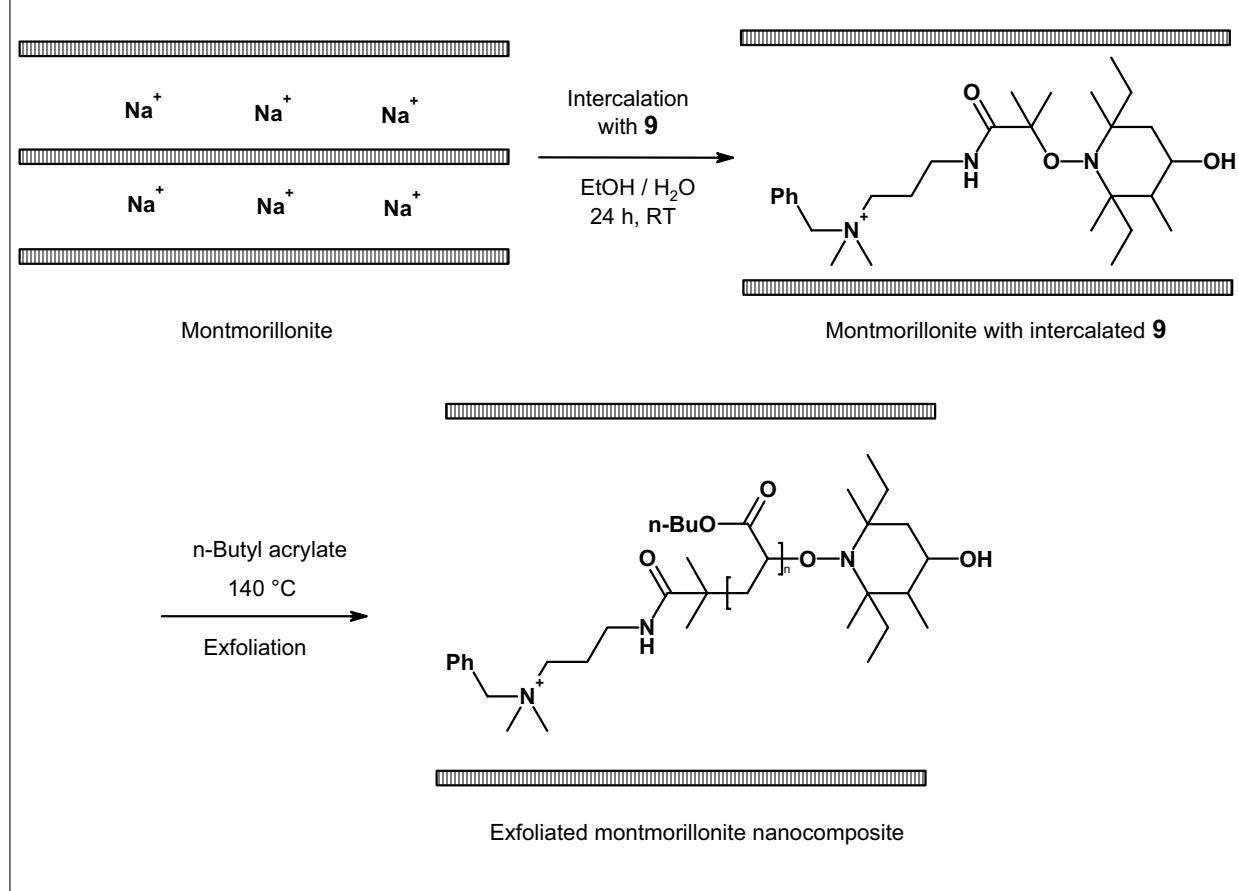

Scheme 3. Intercalation of $\mathbf{9}$ and exfoliation through nitroxide-mediated polymerization

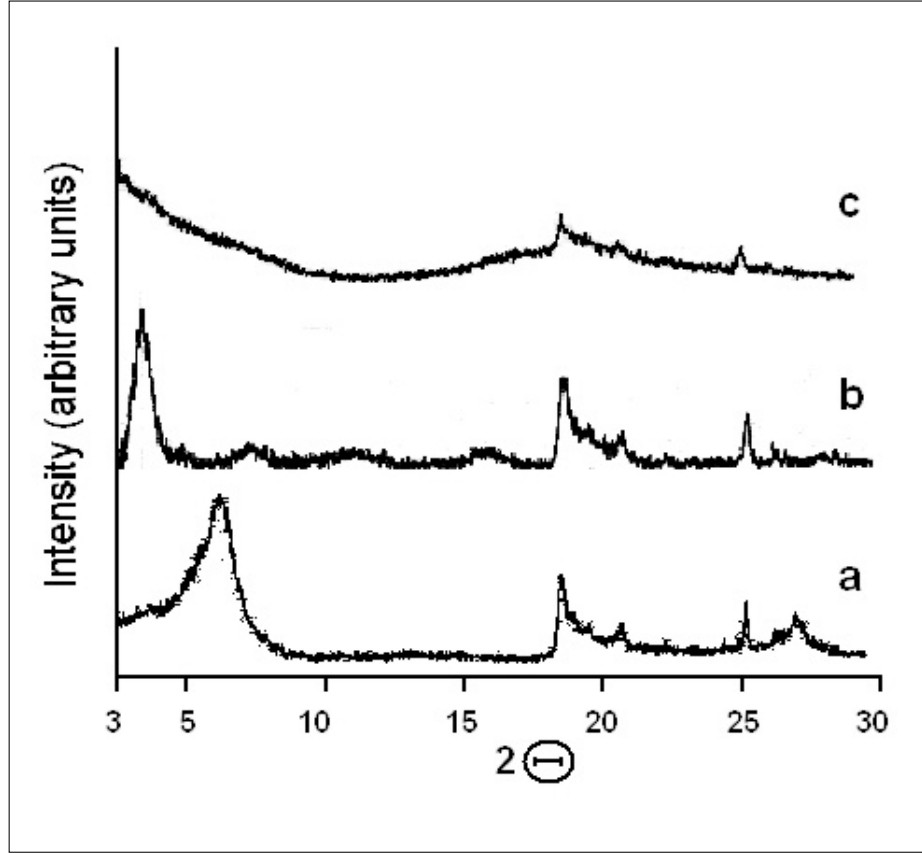

Fig. 2. X-ray diffractograms of a) hydrated Na+-montmorillonite (Nanofil EXM588), b) intercalated montmorillonite with $\mathbf{9}$, and c) exfoliated montmorillonite made by NMP of n-butyl acrylate with intercalated $\mathbf{9}$ (sample $\mathbf{A}$ in the Table)

2.51 three-necked round bottom flask with reflux condenser, magnetic stirring and nitrogen in- and outlet. After evacuation and purging five times with $\mathrm{N}_{2}$, polymerization was performed under $\mathrm{N}_{2}$ for $20 \mathrm{~h}$ at $140{ }^{\circ} \mathrm{C}$ under vigorous stirring. After that time, the monomer conversion, determined by ${ }^{1} \mathrm{H}-\mathrm{NMR}$, was $30 \%$. The solvents were evaporated in the rotavap and the residue extracted in a Soxhlet with 21 EtOAc dur- ing $18 \mathrm{~h}$ to remove all non-attached poly(nbutyl acrylate).[36] After drying in vacuo, $136 \mathrm{~g}$ resin-like material was obtained.

Weight loss in TGA $\left(50-600{ }^{\circ} \mathrm{C}\right): 64.4$ wt\%. X-ray analysis (Fig. 2c): Only peaks at $2 \Theta>10^{\circ}$ are found, arising from atomic distances within the layers and not between the layers, indicating complete exfoliation. In order to cleave off the polymer from the sheet silicate and to analyze the molecular weight of the polymer attached to the individual sheets, a sample $(150 \mathrm{mg})$ of this solid was refluxed with $15 \mathrm{ml} 0.1 \mathrm{M} \mathrm{LiBr}$ solution in THF during $17 \mathrm{~h}$. After filtration, the molecular weight was determined by GPC in THF: $M_{n}=3600, M_{w}=5280$, $\mathrm{PD}=1.47$.

\subsection{Exfoliation of Synthetic Sheet Silicate Optigel SH Containing the Intercalated Cationic Alkoxyamine 9 via NMP of n-Butyl Acrylate.}

$62.3 \mathrm{~g}$ Optigel $\mathrm{SH}$ intercalated with alkoxyamine 9 (41.2 mmol) was dispersed

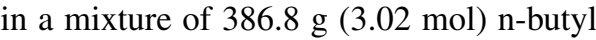
acrylate and $1160 \mathrm{~g}$ 2-methoxypropyl acetate and homogenized with an ultraturrax mixer and ultrasonic bath. The dispersion was transferred to a 2.51 three-necked round bottom flask with reflux condenser, magnetic stirring and nitrogen in- and outlet. After evacuation and purging five times with $\mathrm{N}_{2}$, polymerization was performed under $\mathrm{N}_{2}$ for $20 \mathrm{~h}$ at $140{ }^{\circ} \mathrm{C}$ under vigorous stirring. After that time, the monomer conversion, determined by ${ }^{1} \mathrm{H}-\mathrm{NMR}$, was $25 \%$. The solvents were evaporated in the rotavap and the residue extracted in a Soxhlet with 21 EtOAc during $18 \mathrm{~h}$ to remove all non-attached poly(n-butyl acrylate). ${ }^{[37]}$ After drying in vacuo, $71.4 \mathrm{~g}$ white solid was obtained.

Weight loss in TGA $\left(50-600{ }^{\circ} \mathrm{C}\right): 40.8$ wt\%. X-ray analysis: Only peaks at $2 \Theta$ $>10^{\circ}$ are found, arising from atomic distances within the layers and not between the layers, indicating complete exfoliation. The polymer was cleaved off the sheet silicate by refluxing a sample $(150 \mathrm{mg})$ in 15 $\mathrm{ml} 0.1 \mathrm{M}$ LiBr solution in THF during 17 h. After filtration, the molecular weight determined by GPC in THF, was: $M_{n}=1210$, $\mathrm{M}_{\mathrm{w}}=2300, \mathrm{PD}=1.90$.

\section{Results and Discussion}

\subsection{Synthesis of the Cationic NMP Alkoxyamine Initiator 9}

The target alkoxyamine 9 (Scheme 2) was obtained via straightforward quaternization of the key intermediate $\mathbf{8}$ with benzyl chloride in acetonitrile. The material was obtained as a colorless amorphous solid after the excess of benzyl chloride was washed away with diethyl ether. It is moderately soluble in water or aqueous ethanol. No further purification was attempted. In fact, chromatography would be difficult given the salt character and the compound failed to crystallize, presumably because it is present in form of several diastereoisomers (see refs $[27,38]$ for the discussion of the isomeric composition of 2,6-diethyl2,3,6-trimethylpiperidine nitroxides). The intermediate $\mathbf{8}$ was prepared via the atom transfer radical addition (ATRA) coupling 
reaction[39] of the known ${ }^{[28]}$ nitroxide $\mathbf{5}$ with the activated bromoamide 7 promoted by excess amount of $\mathrm{Cu}(\mathrm{I})$ ions in the presence of $\mathrm{N}, \mathrm{N}, \mathrm{N}$, N ", N"-pentamethyldiethylenetriamine (PMDTA) ligand. The bromoamide 7 was readily obtained via acylation of 3-dimethylamino-propylamine with 2-bromoisobutyryl bromide.

\subsection{Polymerization of n-Butyl}

\section{Acrylate with Alkoxyamines 8 and 9}

Both alkoxyamines $\mathbf{8}$ and $\mathbf{9}$ are efficient mediators of bulk NMP of n-butyl acrylate affording 71 resp. $65 \%$ monomer conversion after $7 \mathrm{~h}$ polymerization at $140{ }^{\circ} \mathrm{C}$. The calculated $\mathrm{M}_{\mathrm{n}}$-values correspond well to those obtained and the polydispersities $(\mathrm{PD}=1.21$ resp. 1.34$)$ of the polymers are rather low.

\subsection{Intercalation of Natural and Synthetic Sheet Silicate with Cationic Alkoxyamine 9}

Cation exchange of the natural and synthetic sheet silicates and intercalation of the cationic alkoxyamine $\mathbf{9}$ was conducted in aqueous ethanol ( $85 \%$ water). Almost quantitative exchange of $\mathrm{Na}^{+}$ions with the cationic alkoxyamine is proven by gravimetric analysis and powder $\mathrm{X}$-ray diffraction. The unmodified montmorillonite (Fig. 2a) shows the most important reflection peak at $2 \Theta=7.1^{\circ}$, corresponding, as calculated according to Bragg's equation $(\mathrm{n} \lambda=2 \cdot \mathrm{d} \cdot \sin \Theta)$, to the original distance between sheets of $d$ $=1.24 \mathrm{~nm}$. Fig. $2 \mathrm{~b}$ displays the powder Xray of the montmorillonite sample, intercalated with 9. The maximum reflection peak is shifted to $2 \Theta=3.86^{\circ}$, corresponding to the new interlayer distance of $\mathrm{d}=2.21 \mathrm{~nm}$. Note that the peak at $2 \Theta=7.1^{\circ}$ has completely disappeared whereas the peaks at higher $2 \Theta$-values are still there since they represent atomic distances within the layers. Therefore, compared with the native sheet silicate, an increase of the interlayer distance of $0.97 \mathrm{~nm}$ is obtained, corresponding approximately to the size of the intercalated 9. Unfortunately, for unknown reasons, we were not able to measure a meaningful X-ray diffraction diagram for the synthetic sheet silicate Optigel SH intercalated with 9.

The exact amount of intercalated 9 was determined by thermogravimetric analysis (TGA) on completely dried samples. Upon heating from r.t. to $600{ }^{\circ} \mathrm{C}$ (heating rate: 10 ${ }^{\circ} \mathrm{C} / \mathrm{min}$ ), a weight loss of $27.1 \%$ was found for the intercalated Nanofil and $31.5 \%$ for the intercalated Optigel, corresponding to the amount of organic material between the layers. These values agree well with the difference in solution concentrations measured by UV-spectroscopy before and after the intercalation process ${ }^{[34]}$ and the final yields. From these data, the ion-exchange capacities of the sheet silicates for the cat-

Table. Exfoliation of natural (Nanofil EXM 588) and a synthetic (Optigel SH) sheet silicates, intercalated with 9, using NMP of n-butyl acrylate (BA) in methoxypropylacetate (MPA) solution at $140{ }^{\circ} \mathrm{C}$

\begin{tabular}{|c|c|c|c|c|c|c|}
\hline $\begin{array}{l}\text { Sample } \\
\text { No. }\end{array}$ & $\begin{array}{l}\text { Sheet } \\
\text { silicate }\end{array}$ & $\begin{array}{l}\text { Mol. \% } 9 \text { in } \\
\text { BA, wt \% BA } \\
\text { in MPA }\end{array}$ & $\begin{array}{l}\text { Time, } \\
\text { Conversion }\end{array}$ & $\mathrm{M}_{\mathrm{n}}$ (calc) & $\begin{array}{l}M_{n}, M_{w} \\
P D(\exp )\end{array}$ & $\begin{array}{l}\text { wt.\% Polymer } \\
\text { in sheet } \\
\text { silicate }\end{array}$ \\
\hline A & $\begin{array}{l}\text { Nanofil } \\
\text { EXM } 588\end{array}$ & $1.37,25 \%$ & 20 h, $30 \%$ & 3280 & $\begin{array}{l}3600,5280 \\
1.47\end{array}$ & 64 \\
\hline B & $\begin{array}{l}\text { Nanofil } \\
\text { EXM } 588\end{array}$ & $0.67,48 \%$ & 24 h, $30 \%$ & 6240 & $\begin{array}{l}6360,12220 \\
1.92\end{array}$ & 78 \\
\hline C & $\begin{array}{l}\text { Nanofil } \\
\text { EXM } 588\end{array}$ & $0.40,100 \%$ & 24 h, 33\% & 11040 & $\begin{array}{l}13700,28700 \\
2.09\end{array}$ & 89 \\
\hline D & $\begin{array}{l}\text { Optigel } \\
\text { SH }\end{array}$ & $1.47,25 \%$ & 20 h, $25 \%$ & 2660 & $\begin{array}{l}1210,2300 \\
1.90\end{array}$ & 41 \\
\hline
\end{tabular}

ionic alkoxyamine 9 can be calculated to be $0.57 \mathrm{mmol} / \mathrm{g}$ intercalated natural sheet silicate Nanofil and $0.66 \mathrm{mmol} / \mathrm{g}$ intercalated synthetic sheet silicate Optigel. These values are slightly lower than the specified values of 0.61 and $0.78 \mathrm{mmol} / \mathrm{g}$, respectively. Presumably, the quite large cation of 9 cannot replace all cations of the native sheet silicates completely due to steric constraints.

\subsection{Exfoliation of Natural and Synthetic Sheet Silicates by NMP}

5-20 wt.\% of two intercalated sheet silicates, containing the immobilized $\mathbf{9}$, were well dispersed in a mixture of n-butyl acrylate (monomer) and 2-methoxypropyl acetate (solvent) and polymerized with vigorous stirring under $\mathrm{N}_{2}$. In order to avoid a highly viscous reaction mixture or even gelling, the appropriate amount of solvent was chosen and the monomer conversion was kept below 33\%. After exfoliation, the dispersion was very homogeneous and stable since rigorous centrifugation gave only a very small amount $(<8 \%)$ of sedimented product, probably non-exfoliated sheet silicate. Evaporation of all monomer/ solvent in high vacuo led to waxy or solid residues. These were extracted with ethyl acetate to remove all non-attached polymer ${ }^{[40]}$ and dried. TGA analysis revealed the polymer layered silicate composition and X-ray analysis gave only peaks at $2 \Theta$ $>10^{\circ}$, arising from atomic distances within the layers and not between the layers Since the smallest $2 \Theta$-value measurable with our instrument is $3^{\circ}$, the $\mathrm{d}$ spacing is $>3 \mathrm{~nm}$, indicating complete exfoliation. In order to analyze molecular weight and polydispersity of the immobilized polymer, it was cleaved off the silicate surface by refluxing the nanocomposite suspension in THF in the presence of $\mathrm{LiBr}$ for an extended period of time. ${ }^{[15]}$ This caused a cation exchange as the $\mathrm{Li}^{+}$-ions replace the polymer's cationic end groups, thus separating the polymer from the insoluble silicate. After filtration molecular weight
$\left(\mathrm{M}_{\mathrm{n}}, \mathrm{M}_{\mathrm{w}}\right)$ and polydispersity PD were determined by GPC in THF (relative to PSstandards).

The results of all exfoliation experiments are summarized in the Table. Depending on the monomer to initiator ratio and the monomer concentration, the number average molecular weight $\mathrm{M}_{\mathrm{n}}$ of the poly(n-butyl acrylate), attached to the individual sheet silicate layers, could be adjusted to be between 1000 and $14000 \mathrm{~g} / \mathrm{mol}$, translating into a polymer weight content of $41-89 \%$. Due to steric constraints between the layers, which is particularly the case at the beginning of the polymerization, the monomer conversion was lower than in the corresponding bulk polymerization experiments (see Experimental Section) and larger PDs were obtained. Nevertheless, the polymerization was somewhat controlled since the calculated molecular weights are in quite good agreement with the obtained values.

An exception is the exfoliation of the synthetic silicate Optigel SH where most of the formed polymer is not attached and the molecular weight of the attached polymer approximately two times lower than calculated. In synthetic sheet silicates, the area of the individual silicate layers are generally much smaller $(<100 \mathrm{~nm}$ in $\mathrm{x}$, y-direction compared to $200-500 \mathrm{~nm}$ for montmorillonite) and therefore we assume that most of the exfoliated product is lost during soxhlet extraction, leaving just sheet silicate with short poly(n-butyl acrylate) chains behind.

Finally, a classical thermal radical initiator, $\quad \alpha, \alpha^{\prime}$-azodiisobutyramidinedihydrochloride was intercalated into Nanofil EXM 588 in order to directly compare the above-described exfoliation by NMP with exfoliation via uncontrolled polymerization. ${ }^{[41]}$ The TGA and GPC results showed clearly that only a small fraction of the intercalated thermal radical initiator is active in polymerization, which is strikingly different to the exfoliation by NMP.

Therefore, it can be concluded, that the exfoliation of montmorillonite-type layered silicates with efficient initiation in all layers 
due to intercalated 9 followed by controlled radical polymerization is a much better method to obtain real nanocomposites in high yield. The amount of non-exfoliated layered silicate is small and the formed polymer has a much lower, controlled molecular weight. This translates into a higher sheet silicate content of the nanocomposite and a lower dispersion viscosity, which is very important for most applications. Furthermore, the exfoliated sheet silicates can be re-dispersed easily in solvents like THF, EtOAc, BuOAc, toluene etc. and the dispersions can be centrifuged during many hours without any sedimentation. Since even diluted dispersions (e.g. $1 \%$ in EtOAc) remain stable for years without visible sedimentation, we conclude that near complete exfoliation to $\mathrm{nm}$ size particles took place.

\section{Application Results: Reduction of Oxygen Permeability in PE foils}

Polyethylene foils were extruded with 3 wt.\% of the unmodified Nanofil EXM 588 and $5 \mathrm{wt} \%$ of the exfoliated montmorillonite-type sheet silicate (sample A, Table). The incorporation of $3 \%$ unmodified sheet silicate increased the oxygen permeability around $10 \%$ (probably due to voids at the organic/inorganic interphase because of lack of compatibility), whereas 5\% A decreased the $\mathrm{O}_{2}$-permeability to about $75-80 \%$ of the original value. Since the exfoliated platelets incorporated into the PE matrix are presumably not ordered the effect is relatively small and thus probably not sufficient for commercial applications.

\section{Conclusions}

We have disclosed an efficient route towards nanocomposite based on the intercalation of a natural and a synthetic sheet silicate by cation exchange with cationic alkoxyamine initiator/regulator 9. Other suitable cationic alkoxyamines are accessible in just a few synthetic steps. Nanocomposites were obtained by thermally induced NMP of n-butyl acrylate, leading to almost complete exfoliation of the silicate layers. Such nanocomposites show increased gas barrier properties. Screening for other possible applications of these unique hybrid nanomaterials is currently in progress.

\section{Acknowledgements}

We thank Ms. F. Modoux for the X-ray measurements and Mr. C. Gerst for providing the TGA and DSC data. Dr. Engelhardt from SüdChemie, Germany is gratefully acknowledged for the Nanofil EXM 588 and Optigel SH sheet silicate samples.

Received: March 27, 2008
[1] E. P. Giannelis, Adv. Mater. 1996, 8, 29.

[2] C. Zilg, R. Thomann, R. Muelhaupt, J. Finter, Adv. Mater. 1999, 11, 49.

[3] C. J. G. Plummer, L. Garamszegi, Y. Leterrier, M. Rodlert, J.-A. E. Maanson, Chem. Mater. 2002, 14, 486.

[4] C. Zilg, F. Dietsche, B. Hoffmann, C. Dietrich, R. Mulhaupt, Macromol. Symp. 2001, 169, 65 .

[5] D. Schmidt, D. Shah, E. P. Giannelis, Curr. Opin. Solid State Mater. Sci. 2002, 6, 205.

[6] Q. T. Nguyen, D. G. Baird, Adv. Polym. Technol. 2006, 25, 270 .

[7] M. Okamoto, Int. Polym. Process. 2006 21, 487.

[8] P. A. Wheeler, J. Wang, J. Baker, L. J. Mathias, Chem. Mater. 2005, 17, 3012.

[9] H. Van Olphen, 'An Introduction to Clay Colloid Chemistry', Willey-Interscience, New York, 1977.

[10] P. B. Messersmith, E. P. Giannelis, Chem. Mater. 1994, 6, 1719.

[11] H. Boettcher, M. L. Hallensleben, S. Nuss, H. Wurm, J. Bauer, P. Behrens, J. Mater. Chem. 2002, 12, 1351.

[12] D. Kubies, N. Pantoustier, P. Dubois, A. Rulmont, R. Jerome, Macromolecules 2002, 35, 3318.

[13] C. J. B. Mott, Catal. Today 1988, 2, 199.

[14] L. P. Meier, R. A. Shelden, W. R. Caseri, U. W. Suter, Macromolecules 1994, 27, 1637.

[15] U. Velten, R. A. Shelden, W. R. Caseri, U. W. Suter, Y. Li, Macromolecules 1999, 32 , 3590.

[16] M. Albrecht, S. Ehrler, A. Muhlebach, Macromol. Rapid Commun. 2003, 24, 382.

[17] W. A. Braunecker, K. Matyjaszewski, Prog. Polym. Sci. 2007, 32, 93.

[18] D. H. Solomon, J. Polym. Sci., Part A: Polym. Chem. 2005, 43, 5748 .

[19] C. J. Hawker, A. W. Bosman, E. Harth, Chem. Rev. 2001, 101, 3661.

[20] C. Konn, F. Morel, E. Beyou, P. Chaumont, E. Bourgeat-Lami, Macromolecules 2007, 40, 7464 .

[21] J. Pyun, K. Matyjaszewski, Chem. Mater. 2001, 13, 3436

[22] M. W. Weimer, H. Chen, E. P. Giannelis, D. Y. Sogah, J. Am. Chem. Soc. 1999, 121, 1615.

[23] J. Di, D. Y. Sogah, Macromolecules 2006 , 39,5052

[24] D. Benoit, V. Chaplinski, R. Braslau, C. J. Hawker, J. Am. Chem. Soc. 1999, 121, 3904.

[25] C. Le Mercier, S. Acerbis, D. Bertin, F. Chauvin, D. Gigmes, O. Guerret, M Lansalot, S. Marque, F. Le Moigne, H. Fischer, P. Tordo, Macromol. Symp. 2002 182, 225.

[26] P. Nesvadba, A. Kramer, M.-O. Zink, DE Patent Publication No. DE99-19949352, 2000.

[27] P. Nesvadba, L. Bugnon, R. Sift, J. Polym. Sci., Part A: Polym. Chem. 2004, 42 3332.

[28] A. Kramer, P. Nesvadba, DE Patent Publication No. DE99-19909767, 1999.

[29] W. Rutsch, M. A. Cech, Chimia 2007, 61, 33.
[30] P. Nesvadba, Chimia 2006, 60, 832.

[31] C. Auschra, E. Eckstein, R. Knischka, P. Nesvadba, Asia Pac. Coat. J. 2003, 16, 20.

[32] A. Muehlebach, P. Nesvadba, A. Kramer, WO Patent Publication No. WO2004000809, 2003.

[33] Measured by the weight loss between 50 and $200{ }^{\circ} \mathrm{C}$ in TGA. The cation exchange capacity is $0.61 \mathrm{mmol} / \mathrm{g}$ or $97.4 \mathrm{mmol}$ exchangeable monovalent cations in the whole sample.

[34] Samples of the dispersion were taken in regular time intervals and the concentration of the alkoxyamine $\mathbf{9}$ in the supernatant clear solution (after centrifugation) was determined by UV-spectroscopy at $\lambda=$ $245 \mathrm{~nm}$, showing that the concentration of the remaining (non-intercalated) 9 is constant (and therefore intercalation terminated) after approx. $20 \mathrm{~h}$ at these conditions.

[35] Measured by the weight loss between 50 and $200^{\circ} \mathrm{C}$ in TGA. The cation exchange capacity is $0.78 \mathrm{mmol} / \mathrm{g}$ or $97.8 \mathrm{mmol}$ exchangeable monovalent cations in the whole sample.

[36] The total amount of extractables was 7.1 $\mathrm{g}$ which corresponds to $\mathrm{ca}$. $8 \%$ of the polymer formed.

[37] The total amount of extractables was 68.1 g which corresponds to $c a$. $70 \%$ of the polymer formed.

[38] H. Fischer, A. Kramer, S. R. A. Marque, P. Nesvadba, Macromolecules 2005, 38 , 9974.

[39] J.-L. Couturier, O. Guerret, T. Senninger, WO Patent Publication No. WO2000061544, 2000.

[40] The relative amount of extracted nonattached poly(n-butyl acrylate) was small in the exfoliated montmorillonite Nanofil (ca. 8\%) but large $(c a .70 \%)$ in the synthetic sheet silicate.

[41] $\alpha, \alpha^{\prime}$-Azodiisobutyramidine-dihydrochloride was intercalated into NanofilEXM 588 to obtain an initiator concentration of $99.2 \mathrm{mg}$ per $1 \mathrm{~g}$ of intercalated product $(0.49 \mathrm{mmol} / \mathrm{g})$. n-Butyl acrylate $(9.5 \mathrm{~g})$ was then polymerized under $\mathrm{N}_{2}$ with 0.5 $\mathrm{g}$ of this intercalated sheet silicate for $3 \mathrm{~h}$ at $80^{\circ} \mathrm{C}$. The dispersion was diluted with toluene $(240 \mathrm{ml})$ and centrifuged to give $0.35 \mathrm{~g}(70 \%)$ of sedimented intercalated Nanofil EXM 588, as verified by TGA and $\mathrm{X}$-ray analysis. The remaining monomer and solvent in the supernatant was evaporated in vacuo. The residue $(2.00$ g) contained, according to TGA-analysis, 93\% polymer and only $7 \%$ sheet silicate. GPC analysis of this residue showed $c a$. $50 \%$ 'free' polymer (not attached to the sheet silicate) with $\mathrm{Mn}=790000$ (PDI $=1.90)$ whereas the attached polymer (ca. $50 \%$, detachment by reflux with 0.1 $\mathrm{M} \mathrm{LiBr}$ in THF) showed $\mathrm{Mn}=660000$ (PDI $=2.06)$, indicating uncontrolled polymerization. 